\title{
Jaime Eduardo Ortiz Varón
}

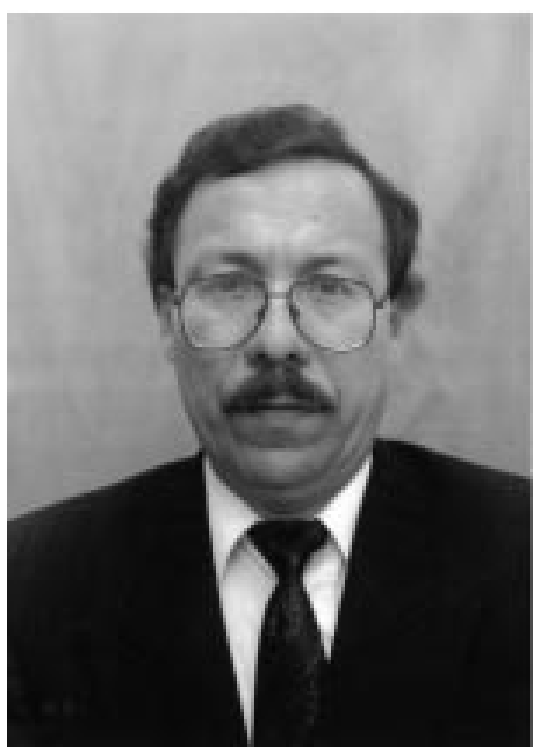

El pasado 13 de julio falleció Jaime Eduardo Ortiz Varón después de dos décadas de haberle contribuido al Instituto Nacional de Salud y a la salud pública del país. Estableció programas de importancia en salud pública desde el Instituto Nacional de Salud y su trabajo fue el pilar fundamental para el fortalecimiento de la gestión de la calidad del agua para consumo humano en el país, estableciendo políticas en la nueva normativa de cómo realizar la vigilancia y el control de la calidad del recurso hídrico, los cuales sustentan la formulación de políticas nacionales y planes de acción regional y municipal, además de los mecanismos de intervención intersectorial.

Además de destacarse por sus valores personales, era reconocido por su entrega y dedicación al trabajo, y por propiciar las buenas relaciones y la conservación de la fraternidad entre quienes lo conocimos. Estuvo vinculado al Grupo de Salud
Ambiental de la Subdirección Red Nacional de Laboratorios desde 1987 y fue coordinador del mismo, desde 1993. Graduado en Química de la Universidad Nacional de Colombia en 1987, complementó sus estudios de posgrado en Salud Ambiental en la Universidad El Bosque en el 2000.

Fue investigador principal en muchos proyectos de gran importancia a nivel nacional, entre ellos las investigaciones y los análisis especializados de muestras biológicas y ambientales para generar conocimiento del impacto del medio ambiente en la salud de la población colombiana, por lo cual recibió reconocimiento de varias entidades nacionales e internacionales por su capacidad de liderazgo y aporte en lo relacionado con el agua potable y la salud ambiental y las muchas otras actividades que lideró en garantía de calidad, diagnóstico y respuesta oportuna a emergencias.

Profesional serio, responsable, comprometido con la institución, desde su infancia demostró su esfuerzo, capacidad de trabajo y responsabilidades que se le reconocía en la labor profesional. Se distinguía por entregar su tiempo sin reparos, por su exigencia consigo mismo y por su rigor y pulcritud en el trabajo; además, por su amplia experiencia en docencia y pedagogía, su saber y talento lo ponía en pro de la educación y la formación de los nuevos funcionarios que ingresaban al grupo y de los demás personas que a nivel nacional, regional y local requerían de sus conocimientos.

El Instituto Nacional de Salud lamenta con sinceridad su partida y expresa las más sentidas condolencias a su familia, esposa e hijos, y nos quedan los más hermosos recuerdos de este gran amigo, compañero y profesor. 